\title{
Exploring Blockchain Value Creation: The Case of the Car Ecosystem
}

\author{
Ingrid Bauer \\ University of Zurich \\ bauer@ifi.uzh.ch
}

\author{
Liudmila Zavolokina \\ University of Zurich \\ zavolokina@ifi.uzh.ch
}

\author{
Fabian Leisibach \\ University of Zurich \\ fabian.leisibach@gmail.com
}

\author{
Gerhard Schwabe \\ University of Zurich \\ schwabe@ifi.uzh.ch
}

\begin{abstract}
Blockchain is expected to create a variety of new opportunities for businesses. Yet, little is known about how companies can exploit business value from the technology. However, without a clear understanding of how, and corresponding adaption of business practices, the realization of value is doomed to failure. Hence, we contribute to this gap by analyzing and explicating the specificities of value creation from blockchain in the ecosystem of a car. In the course of an exploratory case analysis we conducted interviews and workshops with industry and blockchain experts from five diverse stakeholder groups. In brief, we provide early evidence that (1) blockchain enables value creation through: Distributed Product Innovation, Controlled Customer Intimacy and Shared Operational Efficiency. Further, (2) we derive guidelines and discuss learnings for other businesses aiming to leverage value from blockchain technology.
\end{abstract}

\section{Introduction}

Whenever a company embraces a new technology they aim for some form of value generation to either create or to sustain competitive advantage [1]. This also applies for blockchain, the technology that is expected to have great impact on a vast variety of industries [2]. Thus, many companies today are forming consortia, and spending time and resources exploring the potential of the technology with the hope of creating new business value for their companies. According to IDC's (International Data Corporation) worldwide semiannual blockchain spending guide $\$ 945$ million was spent on blockchain solutions in 2017. This amount is expected to reach $\$ 2.1$ billion during 2018 [3]. We have seen many proof-ofconcepts showing that blockchain can provide valuable solutions to existing problems, for example mitigating transactional risk in the Bill of Lading

\footnotetext{
1 With car ecosystem we refer to all business areas along the lifecycle of a car after production.
}

process [4] or solving information asymmetries in the market for lemons [5]. However, despite great investments and promising benefits, it is not yet clear how companies will be able to exploit business value from the technology. Given this ambiguity, managers struggle in the adaption of blockchain to their businesses when moving from prototyping to implementation phase. Taking a business perspective and focusing on the problems of managers, who aim to maximize the business value from the technology, we raise the following research questions:

$R Q$ 1: How can blockchain enable companies to create value in the car ecosystem ${ }^{l}$ ?

$R Q$ 2: What guidelines can we derive for other businesses aiming to create value from blockchain?

To answer these questions, we conducted an exploratory study in the course of a larger Action Design Research [6] project called Car Dossier and applied the theoretical lens of Treacy and Wiersema [7] to explicate the value potential from blockchain.

Car Dossier is a joint European project including multiple stakeholders, ranging from a car importer and retailer, a road-traffic authority, an insurance company, and a car-sharing company, each acting as representatives for their respective industries. These diverse stakeholders collaborate to build a blockchainbased platform that allows to store all relevant data, during the life-cycle of a car, in order to better serve the car ecosystem in a variety of use-cases. Thus, these stakeholders will interact with each other on the basis of blockchain, in order to store and process data. In the following, we will use the term 'the consortium', when we refer to collaborative activities including all of the above-mentioned stakeholders. When taking the specific lens of one of the stakeholders, we will use the following abbreviations: insurer, car retailer, roadtraffic authority (RTA), Car Sharing Company (CSC).

To reach our research objective, we conducted semi-structured expert interviews, held workshops with all stakeholders individually and jointly, and used conceptual modelling of business processes and dataflows. Overall we conducted three iterative 
exploration steps which resulted in: (1) a deeper understanding of the problem- and solution-space, (2) a thorough literature review and the adaption of scholarly concepts to explain observed phenomena (RQ1), and finally (3) derive guidelines from the results and discuss the learnings from our case and answer RQ2. The paper is structured as follows: in section 2 we depart from digital technologies and digital innovation, we introduce blockchain, and describe the three value disciplines that served as our theoretical lens to analyze the business potential in the Car Dossier project. Section 3 describes the applied methods, and section 4 presents the results. In section 5 we derive guidelines from our case and discuss learnings for other practitioners. Finally, section 6 presents limitations, future outlook and conclusions.

\section{Background Literature}

\subsection{Digital technology and digital innovation}

Many determinants need to be evaluated to define how a firm achieves and sustains competitive advantage. While the business model and the environment have been characterized as key determinants that directly influence a company's success, change is claimed to impact both, the business model and the environment in which businesses compete [8], [9]. Hence, change, that can arise from many sources (e.g. competitors, suppliers, customers, or technology) indirectly affects a company's performance [8]. Today, digital technologies account for one of the greatest sources of change due to the continuously accelerating rate of innovation that again result in novel technologies [11]-[13]. If companies miss out these opportunities, just as the formation of the internet economy has shown, digital technologies can very quickly change how business is being done and render existing business models obsolete [14]. Thus, making the determinants of successful firms not static but rather dynamic that require constant innovation [9]. Narrowing the concept of innovation, Fichman et. al. [12] defined digital innovation as " $a$ product, process, or business model that is perceived as new, requires some significant changes on the part of adaptors, and is embodied in or enabled by IT". This definition incorporates both product [15] and process innovation [13], [16], [17] but also business model innovation [9], a more recent class of innovation in IS research. Hence, following this definition, every new digital technology that requires significant change calls for digital innovation. Blockchain, a technology that comes with many new properties, is often claimed as being such a disruptive game changer with the potential to transform existing businesses or even create entirely new industries [18], [19], [20]. Thus, requires further in-depth analysis to understand how to harness its full potential [2].

\subsection{Blockchain Technology}

Evolving from, and still most predominantly known for, blockchain is the underlying technology of Bitcoin, a decentralized virtual currency and since then raised a lot of attention for other applications [5], [21], [22]. In its essence, blockchain is a distributed ledger maintained and shared between nodes in a decentralized peer-to-peer network [23]-[25]. All nodes share the same copy of the ledger, and changes are reflected immediately to all participants of the network. To ensure a single version of truth, all transactions are agreed upon through consensus. More specifically, entries in a blockchain are only accepted if they build on honest pervious entries and adhere to predefined protocols, ensuring tamper-proofness and validity [4], [26]. Despite various systematizations of the key characteristics of blockchain, delimiting it from mere distributed databases [4], analyzing the interrelations of its key characteristics [27], or applying a layered perspective [28], currently there is no unified definition of blockchain in literature. This might be due to the fact that there is no 'one and only' blockchain, but rather different instantiations of its key constructs. Specifically, variations in the properties regulating access rights to transactions have created grounds for classification [29]. Table 1 gives an overview about current classification of blockchain types, along the two dimensions: (a) read and write access, and (b) validation rights to transactions.

Table 1. Blockchain types

(based on Peters \& Panayi [29])

\begin{tabular}{|c|l|l|}
\hline $\begin{array}{l}\text { Access to } \\
\text { Transaction: }\end{array}$ & \multicolumn{2}{|l|}{ (b) Validation } \\
\hline $\begin{array}{l}\text { (a) Read \& } \\
\text { Write }\end{array}$ & \multicolumn{1}{|l|}{ Permissioned } & $\begin{array}{l}\text { Permission- } \\
\text { less }\end{array}$ \\
\hline Public & $\begin{array}{l}\text { All nodes can read } \\
\text { and write } \\
\text { transaction, only } \\
\text { approved nodes can } \\
\text { validate transactions. }\end{array}$ & $\begin{array}{l}\text { All nodes can } \\
\text { read, write, and } \\
\text { validate } \\
\text { transactions. }\end{array}$ \\
\hline Private & $\begin{array}{l}\text { Only approved nodes } \\
\text { can read, write, and } \\
\text { validate transactions. }\end{array}$ & Not applicable \\
\hline
\end{tabular}

While, in a public-permissionless blockchain unknown nodes are free to join the network, and read, write, and validate transactions, in a privatepermissioned blockchain, only registered nodes have 
specific rights to perform transactions. Furthermore, a private-permissioned blockchain allows to differentiate between validating and non-validating peers, which regulates the validation of transactions and ledger maintenance. Compared to publicpermissioned blockchain, this enables increased network security and increased scalability performance of the blockchain network [30], [31]. Besides this classification, the concept of enterprise blockchain starts emerging in literature, which refer to blockchain systems that are adapted in a way to fit specific business needs [2]. There are many reasons for the necessity of business adaption of the technology. For example, businesses have to consider privacy concerns of their customers, their own business secrets, and not least legal restrictions to data protection [2], [32]. This also applies for the Car Dossier project, the case that serves as unit of analysis for this research paper. Evaluating the trade-offs of transparency vs. anonymity with respect to read-, write-, and validation- access, considering latest data protection regulations, as well as the trade-offs with respect to performance of transaction processing, the consortium decided to use a private-permissioned blockchain. Comparing the chosen blockchain to centralized technologies, these were legally and organizationally not acceptable for the stakeholders. Finally, other distributed technologies might be available, but at that point of time those were not sufficiently mature to be accepted for this project.

Today, literature in the blockchain domain is in a very early stage. From a high-level category perspective, the two notable categories found in peerreviewed articles gather around technology and economics [33]-[35]. Thus, we follow the calls for further investigation of the business potential of blockchain technology [18], [26], [27].

\subsection{The Value Disciplines}

To explicate potential business value of blockchain we utilized the value disciplines initially described by Treacy and Wiersema [7]. They suggest that businesses must select and excel in one of the three value disciplines: Product Leadership, Customer Intimacy or Operational Excellence, while remaining competitive at the other two. According to the authors, product leadership "means offering customers leading-edge products and services that consistently enhance the customer's use or application of the product, thereby making rivals' goods obsolete" [7]. Excellence in customer intimacy refers to a company's superior ability to match exactly the individual customer needs by segmenting and targeting specifically, compared to its competitors. Finally [7], companies excelling in operational efficiency serve the customers' needs through providing products and services with minimal inconvenience and at the lowest costs possible. Aligning and focusing the operating model on one of these three value disciplines, is not least since the internet economy the key to success for many businesses [14], [36]. As the computer business exemplified, the sudden drastic reduction in interaction costs changed the way companies exchanged goods and services and opened access to unexploited value that was quickly grasped by specialists rather than generalists [14]. Blockchain provides similar potential to reduce transaction costs even further [24], [37], [38], and especially on the application layer provide greater possibility to specialize and focus business operations [28]. Hence, exploring value creation through the value disciplines [7] provides a good tool to analyze the business potential in the Car Dossier project. Furthermore, given the novelty of the technology and the widereaching concept of digital innovation, spanning product, process and business model, through the value disciplines lens we can address all three. This is because on the one hand the value disciplines are broad in the sense that they incorporate the view on a company's culture, business processes, management and IT systems [7] and support key IT design decisions [39]. On the other hand, they give the necessary focus to exploit specific customer values and help to explicate these for our stakeholders on a more operational level. To be comprehensive, Treacy and Wiersema [7] also discuss and provide a lens for companies that excel at more than one of the value disciplines, 'Master of Two' [36]. However, this requires to resolve the tension that exists between each value disciplines first, thus should be considered for analysis at a later stage.

\section{Methodology}

The lack of knowledge of how business value can be created from blockchain is a common problem of current blockchain projects. Thus, informed by a problem with practical relevance [40] we explored this general problem in the course of a larger Action Design Research project [6], the Car Dossier. However, in this paper we solely focus on explicating the value potential from the technology through qualitative data analysis. Drawing on the findings from our case, it is our goal to derive guidelines for the design of a blockchain systems that will allow business value creation for practitioners [40]-[42]. Despite the focus on one project, the multitude and diversity of project partners in this project greatly 
represent the car ecosystem and hence serve as excellent subject for examination. Overall, this exploratory analysis is grounded on four data sources: (1) in total 12 stakeholder interviews (between 50-70 min. each), (2) four consortium workshops (between 40 - 60 min. each), (3) conceptual models, in the form of business process flows or data-models and, (4) further company information that were provided by the stakeholders individually and jointly. The interviews and workshops served the purpose of eliciting information and evaluating results. All interviewees were either subject matter experts or CLevel managers from the partner companies and active participants in the Car Dossier project, participate in regular design and development sessions. Hence, all interview participants shared a common understanding of the blockchain technology they were questioned about. Throughout these iterative exploration and evaluation loops conceptual models were developed and refined. All interviews were conducted as semistructured interviews [43] and later transcribed and analyzed with qualitative data analysis software. For the coding, an open coding process was used [44] and the coded units were phrases, sentences and paragraphs [45]. To increase internal validity and ensure a shared conception of reflection, the codebook was crosschecked between the authors [46]. The goals, applied methods, and conceptual models that we used during the three iterative data collection steps followed both, the guidelines for theory-generating design science research [47], and the guidelines for applying the Value Disciplines as a tool to understand and shape IT decisions [39], and can be summarized as follows:

(1) First we aimed for a clear understanding of the problem and solution space [39], [47] and for that performed two semi-structured interview rounds. (1a) the first interviews were conducted between May and July 2017. Each partner company was interviewed individually to create a general understanding of the specific problem domain [39] of each partner. The questions addressed the overall business model of each company, the specific business area that are related to the Car Dossier project, and finally the goals of each stakeholder with respect to the joint project. This resulted in a process diagram, in ERM-Notation [48], documenting current business processes and especially highlighting potential interfaces to the planned Car Dossier blockchain architecture. The business processes were also evaluated with the project partners individually. (1b) a second interview round was conducted between September and October 2017 and served to further narrow the problem area [39] of each stakeholder, as well as the consortium. Thus, we asked each partner company to described their problem in their own words and outline potential ways for data and information sharing through the joint blockchain infrastructure. This enabled to model future data and process flows [48] for the ecosystem via the planned blockchain architecture which were then evaluated in a joint consortium workshop.

(2) Next, on the basis of these thorough insights, coupled with knowledge from scholarly theories introduced earlier, we derived ideas for future value creation mechanisms. This resulted in 15 high-level business concepts [47] each centering around one of the previously introduced value disciplines [39] targeting the car ecosystem. The idea behind this was to provide each stakeholder and the consortium with three options, focusing on a choice between the value disciplines.

(3) These business concepts were evaluated again through interviews with stakeholders individually and the consortium [47]. Here we specifically focused on the interrelation of the business concepts with the technology [39].

(4) Finally, this allowed us to explicate the value potential from blockchain and abstract knowledge for value creating blockchain design decisions [39], [47].

\section{Results}

In this section we present our results from the qualitative analysis of the third step, the evaluation of the value discipline centered business concepts. We do so by giving specific examples from the Car Dossier project for each of the value disciplines and underpin these with code units. Table 2 shows the roles and affiliation of the interviewees during this step.

Table 2. Interview / workshop participants during the $3^{\text {rd }}$ step (evaluation-phase)

\begin{tabular}{|l|l|l|}
\hline Affiliation & Role & Short name \\
\hline \multirow{4}{*}{$\begin{array}{l}\text { Software } \\
\text { Company }\end{array}$} & $\begin{array}{l}\text { Car Dossier Project } \\
\text { Management }\end{array}$ & SC_PM_1 \\
\cline { 2 - 3 } & $\begin{array}{l}\text { Car Dossier Project } \\
\text { Management }\end{array}$ & SC_PM_2 \\
\hline \multirow{2}{*}{$\begin{array}{l}\text { Importer \& } \\
\text { Retailer }\end{array}$} & C-Level Management & IR_M \\
\cline { 2 - 3 } $\begin{array}{l}\text { Insurance } \\
\text { Company }\end{array}$ & Subject Matter Expert & IR_E \\
\cline { 2 - 3 } $\begin{array}{l}\text { Road } \\
\text { Traffic } \\
\text { Authority }\end{array}$ & Subject Matter Expert & IC_E \\
\hline Car Sharing & Subject Matter Expert & RTA_M \\
Company & C-Level Management & CSC_M \\
\cline { 2 - 3 } & Subject Matter Expert & CSC_E \\
\hline
\end{tabular}

Next to the stakeholders mentioned earlier, the project also involves a Software Company which also participated in the interviews. The Software Company is responsible for system development and project 
management activities. Thus, they share the same understanding of the technology that they were questioned about, as the other interviewees.

Due to space limitations, for each value discipline, we will focus on one business concept and explain on the horizontal level the pervasive character of blockchain enabled value creation. Figure 1 illustrates the blockchain characteristic that emerged as code units from the interview analysis and which were categorized into blockchain capabilities. Finally, enabled by the blockchain characteristics, the blockchain capabilities enable the manifestations of the blockchain value disciplines: Distributed Product Innovation, Controlled Customer Intimacy and Shared Operational Efficiency. The resulting blockchain characteristics and capabilities will be explained in detail in section 4.1 , whereas section 4.2 and 4.3 will only shortly exemplified these, again due to space limitations and to keep the focus on our contribution, the specificities of value creation through blockchain.

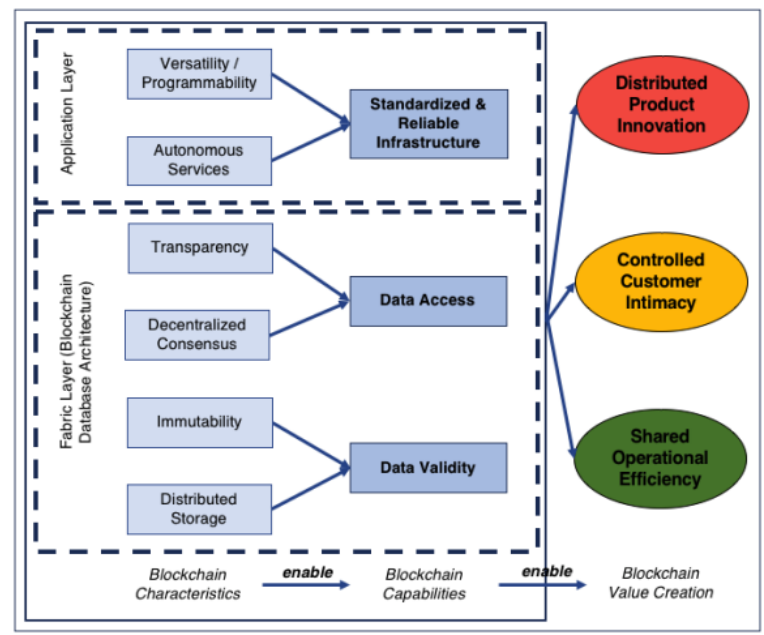

Figure 1. Blockchain enabled value creation

\subsection{Distributed Product Innovation}

From the first two interview rounds we learned that a key problem the consortium aims to solve through blockchain is the information asymmetry between buyers and sellers during the sale of a used car (market for lemons problem in academic literature [49]). This also marks the initial case that brought together the consortium, namely addressing this information asymmetry through a blockchain-based digital dossier, a car dossier, that stores all relevant events during the life-cycle of a car. Thus, the stakeholders aim to store and process all car-related data and information, and jointly create a car dossier for all cars on the market. The justification for blockchain to solve this problem in general was evaluated thoroughly by the stakeholders and also in academia [5]. Still a variety of alternatives exist in how specifically IT might approach this problem. Thus, by questioning through the value discipline lens, we were able to understand the strategic focus of the consortium and the pervasive blockchain characteristics they rely on to create customer value through a car dossier. The consortium showed agreement that they aim for product leadership through providing a new and innovative offering to a yet unserved market. Besides little disagreement whether to classify it as a product or service, the interviewees mentioned: "With the consortium glasses car dossier clearly is a service innovation which solves a clear need, that customer have, but which they might not necessarily be aware of today, (...) I would say there is great unserved potential to leverage through providing this transparency with car dossier." (IC_E). Another said, "It is for sure a quite complex product, however also a very innovative one for our customers" (CSC_M). Once the strategic focus was clearly delineated, during the discussions with the consortium, we further asked about the novelty and necessity of blockchain for creating car dossier. The responses were pretty clear, "Blockchain is the only technology, as of today, that allows all of us to work together." (RTA_M). Another framed it in a paraoxon, "Of course we could solve these collaboration challenges we previously had differently but if we would do so, and evaluate the resulting technology neutrally, we would end up with exactly a solution as blockchain" (SC_PM_1). When we dug deeper and asked what specifically about blockchain it was that enabled them to collaborate and build the car dossier, we managed to ascertain the key blockchain characteristics they rely on. Namely on the one hand, immutability and distributed storage of data. As these two blockchain characteristics were always used jointly or interchangeably to explain the key blockchain capabilities that they relied on, during the coding process we categorized these as the blockchain capabilities enabling: data validity. For example, one manager explained: "The security aspect of blockchain is something of very high priority for us. Data must be safe, immutable and not manipulable by anybody. (...) Being sure about the validity of the data is the alpha and omega for our business, which blockchain provides us now." (RTA_M). On the other hand, the blockchain characteristics, transparency (through sharing data and information), and decentralized consensus (for validating transactions) were mentioned by the consortium as key characteristics that allow increased data access and finally enable them to innovate and create the car dossier. Again, these two characteristics were mentioned not only once, however when the partners, 
for example referred to transparency, they always also emphasized again the reliability of the data entry that they aim to achieve through utilizing decentralized consensus mechanisms. E.g.: "So many changes occur during the life-cycle of a car, sometimes even on a daily basis. Thus, it would not be enough to get a snapshot every now and then, (...) but being able to dynamically have insights to all changes and being sure about these entries is what blockchain-consensus enables us (...)." (IR_M). Vice versa, when they talked about distributed consensus they also emphasized transparency enabling data access: "Through mutual verification we can now trust the data entry of others, and even use what they added to the database to further process it." (RTA_E).

Finally, a third blockchain capability emerged from the characteristics, programmability/versatility and autonomous services, namely the ability to create a standardized and reliable infrastructure. However, when talking about these blockchain characteristics the interviewees mainly referred to the adaptable application logic and the possibilities for implementing smart services, that builds on the underlying key data structure and infrastructure logic. Thus, also in accordance with the literature introduced earlier [28], we grouped the first two capabilities to the fabric layer and the third capability to the application layer. For the car dossier, a product that is created jointly from multiple independent stakeholders, especially the adaptability to their own infrastructure was mentioned as the most important factor. For instance, one manager explained: "We are building a really innovative product with many original owners, thus, allowing individual integration but also aligning different things from different owners is really essential here." (SC_PM_1).

In sum, from our case we learned that blockchain enables product innovation, through enabling companies to create data access and data validity and a reliable and standardized infrastructure which in turn draws on key blockchain characteristics (shown in Figure 1). However, as the above delineated results show, the car dossier is not an innovation of one company alone but arises from the joint efforts of multiple stakeholders. Or as one manager framed it, in this project "all help each other to get better, and this is only possible together." (SC_PM_1). The stakeholders are all experienced in the car market, and also pursue the same interests, which is to serve the needs of buyers and sellers of used cars through providing a novel information product, the car dossier. Yet especially, "the network of partners in this consortium is essential to achieve early market entry and leadership." (SC_PM_2). All stakeholders mentioned that they were aware of this customer need before, yet they lacked the necessary capabilities that enables them provide a trusted solution. Thus, the key difference blockchain makes, is that it goes beyond simply product innovation but enables companies to collaborate and innovate in a distributed manner. Hence, through the creation of a new product, the car dossier that has multiple owners, the stakeholders are able to create value and excel through distributed product innovation.

\subsection{Controlled Customer Intimacy}

Through collaboration over a shared and transparent ledger, the stakeholders discovered that the technology also creates opportunities to even further customize their existing products and services according to niche customer preferences. Hence, allowing the stakeholders to create additional value. This is yet again possible only through increased access to valid data and just as importantly through a reliable and standardized infrastructure. However, access to customer data over the blockchain requires the consent of that customer. Thus, blockchain enables value creation through customization, however in a controlled manner.

One example from our Car Dossier project is the possibility to customize insurance services. Or as one partners summarized it: "Today our insurance premiums and services are packaged the way they are because we lack knowledge. For example, about the quality of a car. Thus, simply said, we have to put all customers in the same pot. Now, through blockchain and the Car Dossier project we would be able to tailor our services better to our customers' needs because we can be sure that we are taking about that specific car with that specificities." (IC_E). Or as another put it more succinctly "blockchain enables us to customize our products better, one example could be object pricing" (IC_M). With respect to the blockchain capabilities they also further elaborated and explained, for instance, increased data access and data validity as follows: "We could also give discounts dynamically because through the blockchain system we can query information, for example about mileage, regularly and hence give you a plus or minus on a quarterly-basis (...). The data might have been collected through one of our partners, or even through dongles automatically, and we need not to bother the customer for that, since we can be sure about the correctness of the data. (...) Plus, we can get access to more data, for example from the importer or the manufacturer, and make more precise evaluations." (IC_M). When we asked why they did not leverage this potential before, we could again elicit that it is specifically the interplay of all three blockchain capabilities that enables them 
now to created value through increased customer intimacy. One expert framed it simply: "It is a matter of trust. Ok, maybe we could trust the importer we collaborate in this project with, however, thinking further we also want to integrate other car importer and retailer which we maybe cannot trust." (IC_E). Yet, blockchain adds a specificity to the customization of products and services: "We have to be careful here. I think intimacy is an unstable balance with blockchain. It is much more a give and take then before. (...) You'll have to build up the trust from the customers to the insurance companies first, so that they will allow you access into their data." (SC_PM_1). What the manager refers to in this specific case also emerged in other examples and hence, we classified it as control by the customer. Since all development effort of the project build on the principle, "we make the customer, the owner of the data, responsible for his or her data him-/herself." (SC_PM_2), customers will no longer have to acquiesce everything. In turn, for our partners this means, "only the one that play fairly get a chance to better customer intimacy. That is something new for businesses we all have to get used to." (SC_PM_1).

All in all, this clearly exemplifies that blockchain allows companies to create value through controlled customer intimacy. On the one hand, the increased access to valid data allows companies to better understand their customers and tailor their services accordingly. On the other hand, standardization of infrastructure and data-formats create low friction for access and inhibit high costs. Yet, the relationship to customers experiences a twist, in a way that they gain increased control over their customization. Thus, value creation, through controlled customization, over blockchain will only function for stakeholders "that rule this game through fair give and take" (SC_PM_1).

\subsection{Shared Operational Efficiency}

Removing mistrust between industry players, blockchain further promises each company to improve operations through sharing processes and leveraging cross-organizational efficiencies. Hence, those companies that focus on the possibilities of reducing transaction costs through sharing processes via blockchain, can achieve shared operational excellence. In the Car Dossier project this is yet another important business case for some of the stakeholders. "The collaboration with regards to business processes is where I see the great value lever." (IR_M). Another stakeholder mentioned: "Blockchain finally allows us to achieve agreement with regards to business processes and resolve inefficiencies." (RTA_E).

To give a specific example, today information flows between customers, car importer, customs and the RTA are characterized by manual processes relying on physical documentation. This leads not too often to poor data quality for the authorities and the importer, but also to inconvenience and doubled work for both, the customers and the stakeholders. Customers have to provide similar details, to multiple stakeholders, in physical forms, and time-consuming ways. One example for this is the import form, a central document during the import process of a car that changes hands multiple times, not only between a customer and stakeholders, but also between businesses directly. Thus, providing great potential for reducing transactions costs through blockchain. Adding to that, blockchain particularly enables cost reduction across organizations. One interviewee stated: "Yes I am pretty sure that, as of today, blockchain is the only technology that allows us to resolve these inefficiencies and jointly digitize these things." (RTA_E). When we further asked "why blockchain', they again most importantly referred to the security aspects of blockchain. "Being sure about data validity and knowing where it comes from, and having the possibility to trace things, is key for authorities like us" (RTA_M). Also, the importer agreed to the necessity of blockchain to digitize these important, and often shared documents in a tamperproof manner. When we asked conversely, they also mentioned the lack of trust in data validity and the lack of possibilities to share these documents in a secure and reliable way as the key reason for not being able to resolve these inefficiencies so far. Finally, the stakeholders agreed that this would lead to increased customer convenience and minimize points of failure at both ends, authorities like RTA and customs, but also businesses operating as car importer. Next to customer convenience, they further stressed the potential for cost reduction that can be leveraged form both, standardization and integration of todays fragmented systems: "The data in general we could also get from customers, that is not the biggest issue today, where I see the biggest value is in the integration of the systems, that leads to cost reductions. This integration aspect, combined with reliable digital data exchange will also allow us to further optimized other processes, for example our fleet management." (IR_M).

Along these lines we exemplified that blockchain promises to enable to share critical processes and documents across organizations, and leverage value through that sharing. Nonetheless, the technology still allows each stakeholder to set their individual foci, e.g. 
on customer convenience like the RTA, or on reducing operational costs like the importer. Hence, all in all blockchain enables both players to excel through shared operational efficiency.

\section{Discussion}

From our conceptualization and evaluation steps with the Car Dossier project, we collected first indication for how blockchain can enable companies to create value in the car ecosystem. Drawing on the blockchain characteristics, which enable the capabilities, our findings suggest blockchain value creation through: Distributed Product Innovation, Controlled Customer Intimacy and, Shared Operational Efficiencies. These insights are valuable for both, researchers and practitioners as they help to understand the potential business value that lies within blockchain platforms. Further, on the basis of these results we derive guidelines that help to guide design decisions in a way to enable business value realization from the technology. Table 3 summarizes the guidelines for each of the blockchain value disciplines, and in the following below, we will discuss what our learnings may mean for other businesses aiming to create value from blockchain.

Table 3. Guidelines for blockchain value creation

\begin{tabular}{|l|l|}
\hline $\begin{array}{l}\text { Blockchain } \\
\text { Value Creation }\end{array}$ & Guidelines for other businesses \\
\hline $\begin{array}{l}\text { Distributed } \\
\text { Product }\end{array}$ & $\begin{array}{l}\text { Put on your consortium glasses and } \\
\text { focus on unserved potential in the } \\
\text { ecosystem rather than your industry } \\
\text { segment. }\end{array}$ \\
\hline $\begin{array}{l}\text { Controlled } \\
\text { Customer }\end{array}$ & $\begin{array}{l}\text { Be aware of the changing (power) } \\
\text { relationships and focus on building } \\
\text { an even greater trust-relationship to } \\
\text { your customers. }\end{array}$ \\
\hline $\begin{array}{l}\text { Shared } \\
\text { Operational } \\
\text { Efficiency }\end{array}$ & $\begin{array}{l}\text { Resolve cross-organizational } \\
\text { inefficiencies jointly but set your } \\
\text { own focus to leverage the full } \\
\text { potential for your business. }\end{array}$ \\
\hline
\end{tabular}

Thus, we provide first evidences for the academic questions raised above and the problems managers currently phase. Further, previous research has claimed that blockchain has the potential for disrupting businesses [19], [20], we add to this by demonstrating how this can be realized in the car ecosystem. More precisely we reveal the blockchain traits on a horizontal level, that penetrate business practices. During our qualitative analysis it emerged that in accordance with previous research [28], also in this project a two-level perspective of blockchain (fabric and application layer) might help to understand the implications of the technology. Yet, focused on the business implications of the technology, we further uncover along that path. Finally, as we have seen that blockchain affects products (car dossier), business models (customization) and processes (sharing of processes) this supports our choice of the value disciplines [7] as an academic lens.

Distributed Product Innovation means that blockchain enables co-creating new products and services across organizations in a distributed way. However, being able to do so, companies need to put on their consortium glasses and focus on the customer needs that might exceed their current industries boundaries. As we have seen from the Car Dossier case, blockchain is a technology that allows to collaborate across industries and jointly create a product like the car dossier to previously unserved customer needs. These customer needs however are not inherent to one company's current primary business focus but rather lay at intersections. Thus, for other companies experimenting with the technology and aiming to create business value, we suggest to join efforts with other players in the same ecosystem and collaborate on research and development, in order to innovate products and services for a joint market.

Controlled Customer Intimacy refers to the ability of companies to achieve excellence in customer intimacy through blockchain, however, in a customercontrolled manner. We exemplified this through the possibilities of customized insurance, yet, while respecting customers' voice. Thus, as some of our stakeholders have already learned from the project, companies that aim to leverage this potential need to build trust to their customers first. This is because a platform like the one of the Car Dossier project does allow increased access to customer data. However, inherent to the characteristics of blockchain it also inhibits unpermitted control. On the one hand this is necessary to allow companies to trust the data they get from other players in the system. On the other hand, this also introduces greater control over data access for customers. Hence, the guideline we derive for other companies that rely on a customer relationship business and aim to create value through blockchain, is to focus on building even greater trust-relationships with their customers. More specifically they should interpret the terming intimacy in a more bilateral sense and build an intimate bilateral relationship, in order to create value through blockchain with the customer.

Shared Operational Efficiency means that blockchain enables companies to minimize overhead costs through sharing processes which in turn enables companies to achieve shared operational excellence. In our case project there were plenty of examples for resolving inefficiency and eliminating intermediary 
steps. One example elaborated above was the case of a car import, where authorities like road traffic authority and customs can digitize and share processes with importer businesses. This allows on the one hand authorities to increase customer convenience. On the other hand, it facilitates opportunities for cost reduction for importer. Both resulting in individually optimized business processes from cross organizational collaboration. Based on these insights from the Car Dossier case, our suggestions for other companies aiming to create value from the technology through better infrastructure management, is to apply a balanced perspective. On the one hand, jointly target cross-organizational inefficiencies with your partners. On the other hand, focus on the specificities of your own business to leverage the full potential from arising unresolved inefficiencies.

While the results and the above-mentioned guidelines show great potential for how businesses can realize the value potential from blockchain, there are also certain hurdles we encountered during our exploration. First, in such a big project multiple interest groups need to be managed. As this analysis exemplifies, there is great potential for all stakeholder, however in different ways. Thus, managing these different interests accordingly, to allow all stakeholder to leverage the potential they are after, is a key activity affecting all. Second, all companies collaborating on the same project for one ecosystem will all have the same potential, independent the industry they are in now. This can induce competition over business potential. Third, the boundaries of customer intimacy need to be respected. Societal questions like reinforcement of two-classes society through too much individualization need to be evaluated carefully. Finally, changing operational processes that incorporate authorities are not as simple. Sometimes even legal groundings are needed for that. Yet, the novelty and constant evolution the technology itself makes it hard for practitioners to initiate legal changes. Thus, despite discovered value potential, leveraging it is yet another hurdle.

\section{Conclusion}

In this paper we address the little attention that was given to blockchain from a business perspective by explicate how businesses can create value from the technology in the car ecosystem. Based on the results from the Car Dossier project, we provide design guidelines for other businesses aiming to create value from blockchain. These insights are valuable not least for (1) academia, as we add to the limited discourse on business potential from blockchain by applying a scientific lens to the value creation and hence providing first answers to open research questions; (2) businesses, through disclosing insights in an advanced blockchain project in a highly-competitive market and providing guidelines for other businesses; (3) society as we emphasize both, the necessity of legislators for adapting and loosening legislation to allow leveraging efficiencies, but also keeping an eye on regulations with respect to customer protection. Yet, our paper has a few limitations. First, our analysis is based solely on the findings of one project. Thus, we recognize future research will be needed to test the generalizability and the applicability of our findings in the selected, and in other domains. Second, even though our project moved beyond mere prototyping phase, it is still in an early design phase, thus the proposed value potential will require testing in practice. Third, we acknowledge the generality of the approach to define the business value of blockchain projects and the need for more fine-grained analysis. This deficit we aim to address through future research, as part of our ongoing collaboration with the Car Dossier consortium. Finally, it has to be noted that blockchain itself is still a recent innovation that might experience further developments which could impact the value creation logic. Thus, our findings should be viewed as an initial step towards a more holistic understanding of the business potential from blockchain.

\section{Acknowledgement}

The "Blockchain Car Dossier" research project has been funded by Innosuisse. We thank all partners for their involvement and feedback, and all reviewers for critical comments that enhanced the research.

\section{References}

[1] J. Peppard and J. Ward, "Beyond strategic information systems: towards an IS capability," The Journal of Strategic Information Systems, vol. 13, no. 2, pp. 167-194, Jul. 2004. [2] V. Morabito, Business Innovation Through Blockchain. Cham: Springer International Publishing, 2017.

[3] M. Shirer and J. Goepfert, "New IDC Spending Guide Sees Worldwide Blockchain Spending Growing to $\$ 9.7$ Billion in 2021," IDC - Analyze the future, 05-Jun-2018. www.idc.com/getdoc.jsp?containerId=prUS43526618.

[4] K. Naerland, C. Müller-Block, R. Beck, and S. Palmund, "Blockchain to Rule the Waves - Nascent Design Principles for Reducing Risk and Uncertainty in Decentralized Environments," the $38^{\text {th }}$ ICIS, South Korea, 2017, p. 16.

[5] B. Notheisen, J. Cholewa, A. Shanmugam, "Trading Real-World Assets on Blockchain," BISE, vol. 59/9, 2017.

[6] Sein, Henfridsson, Purao, Rossi, and Lindgren, "Action Design Research," MIS Quarterly, vol. 35, no. 1, p. 37, 2011. [7] M. Treacy and F. Wiersema, "Customer Intimacy and 
Other Value Disciplines," HBR, Jan-Feb, p. 12, 1993.

[8] D. J. Teece, "Explicating dynamic capabilities: the nature and microfoundations of enterprise performance," Strategic Management Journal, vol. 28, no. 13, 2007.

[9] D. J. Teece, "Business Models, Business Strategy and Innovation," Long Range Planning, vol. 43, no. 2-3, pp. 172-194, Apr. 2010.

[10] A. Afuah and C. L. Tucci, "Internet business models and strategies: text and cases". Irwin/McGraw-Hill, 2001.

[11] H. Chesbrough, "The role of the business model in capturing value from innovation: evidence from Xerox Corporation's technology spin-off companies," Industrial and Corporate Change, (11:3) pp. 529-555, Jun. 2002.

[12] R. Fichman, B. Dos Santos, Z. Zheng, "Digital Innovation as a Fundamental and Powerful Concept in the IS Curriculum," MIS Quarterly, vol. 38, no. 2, 2014.

[13] J. Tidd and J. Bessant, "Managing innovation: integrating technological, market and organizational change, John Wirley \& Sons. 2011.

[14] J. Hagler and M. Singer, "Unbundling the Corporation," HBR, Organizational Structure, March-April, p. 21, 1999.

[15] Y. Yoo, O. Henfridsson, and K. Lyytinen, "The New Organizing Logic of Digital Innovation: An Agenda for Information Systems Research," Information Systems Research, vol. 21, no. 4, pp. 724-735, Dec. 2010.

[16] Kevin C. Desouza, "Intrapreneurship: Managing Ideas Within Your Organization," Univ. of Toronto Press, 2011.

[17] H. W. Chesbrough, "Open innovation: the new imperative for creating and profiting from technology," Harvard Business School Press, Boston Mass., 2003.

[18] M. Avital, R. Beck, J. King, M. Rossi, and R. Teigland, "Jumping on the Blockchain Bandwagon: Lessons of the Past and Outlook to the Future," 37 ${ }^{\text {th }}$ ICIS, Dublin, 2016.

[19] R. Beck, M. Avital, M. Rossi, and J. B. Thatcher, "Blockchain Technology in Business and Information Systems Research," BISE, vol. 59, no. 6, pp. 381-384, 2017. [20] J. Lindman, M. Rossi, and K. T. Virpi, “Opportunities and risks of Blockchain Technologies in payments - a research agenda," 2017.

[21] R. Beck, C. Müller-Bloch, and J. L. King, "Governance in the Blockchain Economy: A Framework and Research Agenda," JAIS, 2018.

[22] R. Böhme, N. Christin, B. Edelman, and T. Moore, "Bitcoin: Economics, Technology, and Governance," Journal of Economic Perspectives, (29:2) p. 213-238, 2015. [23] F. Tschorsch and B. Scheuermann, "Bitcoin and Beyond: A Technical Survey on Decentralized Digital Currencies," IEEE Communications Surveys \& Tutorials, vol. 18, no. 3, pp. 2084-2123, 2016.

[24] R. Beck, J. Stemi Czepluch, L. Nicolaj, and S. Malone, "Blockchain. The Gateway to Trust-free Cryptographic Transactions," 24th ECIS, 2016, pp. 1-14.

[25] M. Sharples and J. Domingue, "The Blockchain and Kudos: A Distributed System for Educational Record, Reputation and Reward," in Adaptive and Adaptable Learning, 2016, pp. 490-496.

[26] N. Rückeshäuser, "Typology of distributed ledger based business models," p. 17, 2017.

[27] S. Seebacher and R. Schüritz, "Blockchain Technology as an Enabler of Service Systems: A Structured Literature Review," in Exploring Services Science, vol. 279, Eds.
Cham: Springer International Publishing, 2017, pp. 12-23. [28] F. Glaser, "Pervasive Decentralization of Digital Infrastructures: A Framework for Blockchain enabled System and Use Case Analysis," 50th HICSS, 2017.

[29] G. W. Peters and E. Panayi, "Understanding Modern Banking Ledgers through Blockchain Technologies: Future of Transaction Processing and Smart Contracts on the Internet of Money," arXiv:1511.05740, Nov. 2015.

[30] X. Xu et al., "A Taxonomy of Blockchain-Based Systems for Architecture Design," in 2017 IEEE (ICSA), 2017, pp. 243-252.

[31] W. Li, A. Sforzin, S. Fedorov, and G. O. Karame, "Towards Scalable and Private Industrial Blockchains," in Proceedings of the ACM Workshop on Blockchain, Cryptocurrencies and Contracts - BCC '17, 2017, pp. 9-14. [32] S. Hamm, "How businesses and governments can capitalize on blockchain," ww.ibm.com/blogs/think/2016/03/16/how-businesses-andgovernments-can-capitalize-on-blockchain/. [20-05-2018].

[33] J. L. Zhao, S. Fan, J. Yan, "Overview of business innovations and research opportunities in blockchain and introduction to the special issue," Financial Innovation, vol. 2, no. 1, 2016.

[34] J. Yli-Huumo, D. Ko, S. Choi, S. Park, and K. Smolander, "Where Is Current Research on Blockchain Technology? - A Systematic Review," PLOS ONE, 2016.

[35] M. Holub and J. Johnson, "Bitcoin research across disciplines," The Information Society, vol. 34, no. 2, 2018.

[36] A. Osterwalder and Y. Pigneur, Business Model Generation. Hoboken, New Jersey, 2010.

[37] M. Iansiti and K. R. Lakhani, "The Truth About Blockchain,” Harvard Business Review, p. 11, 2017.

[38] S. Davidson, P. De Filippi, and J. Potts, "Economics of Blockchain,” SSRN Electronic Journal, 2016.

[39] M. Eichen, "Value Disciplines: A Lens for Successful Decision Making in IT," Educause Quarterly, No. 2, 2006.

[40] A. R. Hevner, S. T. March, J. Park, and S. Ram, "Design Science in Information Systems Research," MIS Quarterly, vol. No. 1, no. 28, pp. 75-105, 2004.

[41] Gregor, "The Nature of Theory in Information Systems," MIS Quarterly, vol. 30, no. 3, p. 611, 2006.

[42] S. Gregor, O. Müller, and S. Seidel, "Reflection, Abstraction and Theorizing In Design And Development Research," the 21st ECIS, 2013, vol. 7-1, p. 13.

[43] M. D. Myers, M. Newman, "The qualitative interview in IS research: Examining the craft," Information and Organization, vol. 17, no. 1, pp. 2-26, Jan. 2007.

[44] J. Saldaña, The coding manual for qualitative researchers. Los Angeles, Calif: Sage, 2009.

[45] R. P. Weber, Basic content analysis. Sage, 1990.

[46] C. Weston, T. Gandell, J. Beauchamp, L. McAlpine, C. Wiseman, and C. Beauchamp, "Analyzing Interview Data: The Development and Evolution of a Coding System," Qualitative Sociology, p. 22, 2001.

[47] R. Beck, S. Weber, R. W. Gregory, "Theory-generating design science research," IS Frontiers, vol. 15, no. 4, 2013.

[48] P. P.-S. Chen, "The Entity-Relationship Model: Towards a unified view of data," MIT, 1976.

[49] G. A. Akerlof, "The market for lemons': Quality uncertainty and the market mechanism," The quarterly journal of economics, pp. 488-500, 1970. 